\title{
Inheritance of Parental Genomes by a Hybrid Form Rana "esculenta" (Amphibia, Ranidae)
}

\author{
S. Yu. Morozov-Leonov ${ }^{a}$, S. V. Mezhzherin ${ }^{a}$, O. D. Nekrasova ${ }^{a}$, D. A. Shabanov ${ }^{b}$, \\ A. V. Korshunov ${ }^{b}$, and F. F. Krutyak ${ }^{c}$ \\ ${ }^{a}$ Schmalhausen Institute of Zoology, National Academy of Sciences of the Ukraine, Kiev, 01601 Ukraine; \\ e-mail:morleone2000@hotmail.com \\ ${ }^{b}$ Kharkov National University, Kharkov, 610077 Ukraine \\ ${ }^{c}$ Uzhgorod National University, Uzhgorod, 88000 Ukraine
}

Received July 10, 2007

\begin{abstract}
In this study, quantitative analysis of paternal genome inheritance by a hybrid form Rana "esculenta" (= Rana esculenta L., $1758 \times$ Rana ridibunda Pall., 1881) (Amphibia, Ranidae) was examined. The hybrid form examined was characterized by a polymodal mode of inheritance (genome of any of the parental species can be inherited). The absence of correlation between the proportion of normal gametes and either sex or ploidity of the producer was demonstrated. The gametes produced could be both haploid and diploid (hybrid or homozygous). The mechanism of alloploid reproduction is discussed.
\end{abstract}

DOI: $10.1134 / \mathrm{S} 1022795409040061$

\section{INTRODUCTION}

The present study was focused on characteristics of the mode of inheritance specific to hybrid frog Rana "esculenta" (Amphibia, Ranidae), which was made based on quantitative analysis of the genotypes of gametes produced by hybrid animals. Hybrid frog Rana "esculenta" is one of the well-known forms of hybrid origin. This frog is characterized by unusual mode of reproduction. The first studies analyzing this phenomenon, showed that Rana "esculenta" individuals produced the gametes containing only the lake frog genome $(\mathrm{LR} \longrightarrow \mathrm{R})[1,2]$. Analogous mode of reproduction (called as hemiclonal) was earlier described in interspecific fish hybrids of the genus Poeciliopsis [3]. Thus, hybrid frog Rana "esculenta" can be reproduced through backcrossing to that parental species, whose genome is not inherited. However, more detailed analysis of the mode of inheritance specific to hybrid Rana "esculenta" frogs showed that it had some specific features. First, in some parts of the species range, hybrid form inherits exclusively of another parental species, the pool frog (LR $\longrightarrow$ L) [4]. Second, in some populations the hybrids produce more than one class of gametes of different genotype and/or ploidity [5]. Finally, in many natural populations contain allotriploids, which are not reproductively isolated from parental species [6]. At the same time, alloploids of the genus Poeciliopsis are characterized by gynogenetic reproduction [7]. For these reasons, the mode of reproduction typical of hybrodogenetic frog Rana "esculenta" cannot be considered as hemiclonal in traditional interpretation of this term.
In this study, quantitative analysis of the inheritance of parental genomes by hybrid frog Rana "esculenta" was performed.

\section{MATERIALS AND METHODS}

Data source. The data on gamete genotypes (shown in Table 1) were taken from the literature and obtained in the present study (for the methods, see below).

Determination of gamete genotypes was performed by means of electrophoretic analysis of germ cell suspension (for males) or individuals eggs (for females). Frogs were caught in 1992 through 2005. Standard methods of sample preparation and electrophoresis were used $[4,8]$.

Sample preparation. Live animals were transported to the laboratory, where they were anesthetized with ethylic ether of 3-aminobenzoic acid and killed. Gonads were removed. To examine mature egg mass from the ovaries by means of electrophoresis, individual eggs were isolated under a binocular micrpscope with the help of preparation needles. Then, the eggs were separated from the tissue fluid by placing on a piece of filter paper for 10 to $20 \mathrm{~s}$. After that, each egg was placed into 1-2-ml tube. The tubes were added with two to three drops of $10 \%$ sucrose solution stained by addition of bromphenol blue. The tubes were closed and frozen for $12 \mathrm{~h}$. After thawing, each egg was squashed in the tube, and the tubes were shacked several times for more complete mixing of the egg content with the sucrose solution. To analyze male germ cells, testes were washed in distilled water, dried on filter paper, and squashed between two slide plates. 
Table 1. Numbers of hybrid frogs Rana "esculenta" with different modes of parental genome inheritance

\begin{tabular}{|c|c|c|c|c|c|c|c|c|c|c|c|c|c|}
\hline \multirow{2}{*}{ Sex } & \multirow{2}{*}{ Soma } & \multicolumn{8}{|c|}{ Gamete genotypes } & \multirow{2}{*}{$n$} & \multirow{2}{*}{$N$} & \multirow{2}{*}{ Method } & \multirow{2}{*}{ Literature source } \\
\hline & & $\mathrm{R}$ & $\mathrm{L}$ & $\mathrm{RR}$ & LL & LR & $\mathrm{L}+\mathrm{R}$ & $L \gg R$ & Oth. & & & & \\
\hline \multicolumn{14}{|c|}{$\begin{array}{l}\text { 1. Western Europe } \\
\text { 1.1. Germany }\end{array}$} \\
\hline \multirow[t]{3}{*}{$q q$} & LR & 3 & 0 & 0 & 0 & 1 & 0 & 0 & 1 & 5 & \multirow{6}{*}{9} & \multirow{6}{*}{$1,2,6$} & \multirow{6}{*}[5,6,9,16,17]{} \\
\hline & LLR & 0 & 2 & 0 & 1 & 0 & 0 & 0 & 0 & 3 & & & \\
\hline & LRR & 1 & 0 & 0 & 0 & 0 & 0 & 0 & 0 & 1 & & & \\
\hline \multirow[t]{3}{*}{ के } & LR & 2 & 16 & 0 & 0 & 0 & 6 & 2 & 0 & 26 & & & \\
\hline & LLR & 0 & 12 & 0 & 2 & 0 & 1 & 10 & 0 & 25 & & & \\
\hline & LRR & 17 & 0 & 0 & 0 & 0 & 0 & 0 & 0 & 17 & & & \\
\hline \multicolumn{14}{|c|}{ 1.2. Denmark } \\
\hline \multirow[t]{2}{*}{$q q$} & LR & 1 & 0 & 0 & 0 & 5 & 0 & 0 & 1 & 7 & \multirow{5}{*}{3} & \multirow{5}{*}{3} & \multirow{5}{*}[15]{} \\
\hline & LLR & 0 & 0 & 0 & 0 & 0 & 0 & 0 & 1 & 1 & & & \\
\hline \multirow[t]{3}{*}{$0^{t}$} & LR & 0 & 0 & 0 & 0 & 0 & 0 & 0 & 1 & 1 & & & \\
\hline & LLR & 1 & 4 & 0 & 0 & 0 & 0 & 0 & 0 & 5 & & & \\
\hline & LRR & 1 & 0 & 0 & 0 & 0 & 0 & 0 & 0 & 1 & & & \\
\hline & & & & & & & 3. Polar & & & & & & \\
\hline q $q$ & LR & 9 & 0 & 0 & 0 & 5 & 2 & 0 & 9 & 25 & & & \\
\hline & LRR & 9 & 0 & 0 & 0 & 0 & 0 & 0 & 1 & 10 & & & \\
\hline $0^{\lambda} 0^{\lambda}$ & LR & 12 & 1 & 0 & 0 & 0 & 1 & 0 & 1 & 15 & 6 & 1,5 & {$[9,16-19]$} \\
\hline & LLR & 0 & 1 & 0 & 0 & 0 & 0 & 0 & 0 & 1 & & & \\
\hline & LRR & 10 & 0 & 0 & 0 & 1 & 0 & 0 & 1 & 12 & & & \\
\hline & & & & & & & Switzer & land & & & & & \\
\hline$q q$ & LR & 7 & 0 & 0 & 0 & 0 & 0 & 0 & 0 & 7 & 3 & 2,5 & {$[2,19,20]$} \\
\hline ô 0 & LR & 2 & 0 & 0 & 0 & 0 & 0 & 0 & 0 & 2 & & & \\
\hline & & & & & & & Yugosl & avia & & & & & \\
\hline$q q$ & LR & 32 & 0 & 0 & 0 & 0 & 0 & 0 & 0 & 32 & 2 & 5 & [21] \\
\hline ô 0 & LR & 2 & 0 & 0 & 0 & 0 & 0 & 0 & 0 & 2 & & & \\
\hline & & & & & & & 5. Austr & & & & & & \\
\hline$q q$ & LR & 47 & 0 & 0 & 0 & 0 & 2 & 0 & 0 & 49 & 1 & $1,2,4$ & {$[19,22-24]$} \\
\hline & & & & & & & Hung & & & & & & \\
\hline ô 0 & LLR & 0 & 0 & 0 & 55 & 0 & 0 & 0 & 0 & 55 & 1 & 2,4 & [24] \\
\hline & & & & & & 2. $\mathrm{E}$ & stern El & rope & & & & & \\
\hline & & & & & & & Ukrai & & & & & & \\
\hline & & & & & & 1.1. D & nube $\mathrm{Ri}$ & ver basin & & & & & \\
\hline & & & & & & 2.1 .1 & Transc & arpatia & & & & & \\
\hline$q$ q & LR & 35 & 0 & 0 & 0 & 0 & 0 & 0 & 0 & 35 & 6 & 5 & Personal data \\
\hline & & & & & 2.1 .1 & Mol & of the & Danube $\mathrm{F}$ & iver & & & & \\
\hline q $q$ & LR & 0 & 8 & 0 & 0 & 0 & 0 & 0 & 0 & 8 & 3 & 5 & $"$ \\
\hline ôt & LR & 0 & 21 & 0 & 0 & 0 & 0 & 0 & 0 & 21 & & & \\
\hline & & & & & & 1.2. D & eper $\mathrm{R}$ & ver basin & & & & & \\
\hline$q q$ & LR & 15 & 0 & 0 & 0 & 1 & 0 & 0 & 0 & 16 & 4 & 2,5 & $"$ \\
\hline ô $0 \hat{0}$ & LR & 32 & 0 & 0 & 0 & 3 & 3 & 0 & 0 & 38 & & & \\
\hline & & & & & & 2.1.3. & on Riv & r basin & & & & & \\
\hline$\hat{0} 0$ & LR & 1 & 5 & 0 & 0 & 1 & 3 & 0 & 0 & 10 & 1 & 5 & $"$ \\
\hline & LRR & 1 & 0 & 0 & 0 & 0 & 0 & 0 & 0 & 1 & & & \\
\hline
\end{tabular}


Table 1. (Contd.)

\begin{tabular}{|c|c|c|c|c|c|c|c|c|c|c|c|c|c|}
\hline \multirow{2}{*}{ z } & \multirow{2}{*}{ Soma } & \multicolumn{8}{|c|}{ Gamete genotypes } & \multirow{2}{*}{$n$} & \multirow{2}{*}{$N$} & \multirow{2}{*}{ Method } & \multirow{2}{*}{ Literature source } \\
\hline & & $\mathrm{R}$ & $\mathrm{L}$ & RR & $\mathrm{LL}$ & LR & $\mathrm{L}+\mathrm{R}$ & $L \gg R$ & Oth. & & & & \\
\hline \multicolumn{14}{|c|}{ Ukraine, overall } \\
\hline$q q$ & LR & 50 & 8 & 0 & 0 & 1 & 0 & 0 & 0 & 59 & \multirow[t]{3}{*}{14} & \multirow[t]{3}{*}{2,5} & \\
\hline $0^{\pi} 0^{2}$ & LR & 33 & 26 & 0 & 0 & 4 & 6 & 0 & 0 & 69 & & & \\
\hline & LRR & 1 & 0 & 0 & 0 & 0 & 0 & 0 & 0 & 1 & & & \\
\hline \multicolumn{14}{|c|}{ 2.2. Belarus } \\
\hline ô 0 & LR & 3 & 0 & 0 & 0 & 0 & 0 & 2 & 0 & 5 & 1 & 6 & {$[16]$} \\
\hline \multicolumn{14}{|c|}{ 2.3. Latvia } \\
\hline ôt & LR & 29 & 0 & 0 & 0 & 0 & 0 & 0 & 0 & 29 & 2 & 6 & {$[25,26]$} \\
\hline \multicolumn{14}{|c|}{ 2.4. Russia } \\
\hline ô 0 & LR & 2 & 11 & 0 & 0 & 0 & 3 & 0 & 0 & 16 & 2 & 6 & {$[17]$} \\
\hline \multicolumn{14}{|c|}{ Europe, overall } \\
\hline \multirow[t]{3}{*}{$q q$} & LR & 149 & 8 & 0 & 0 & 12 & 4 & 0 & 11 & 184 & \multirow{7}{*}{44} & & \\
\hline & LLR & 0 & 2 & 0 & 1 & 0 & 0 & 0 & 1 & 4 & & & \\
\hline & LRR & 10 & 0 & 0 & 0 & 0 & 0 & 0 & 1 & 11 & & & \\
\hline ठิ & LR & 86 & 54 & 0 & 0 & 4 & 18 & 4 & 2 & 168 & & & \\
\hline & LLR & 1 & 17 & 0 & 57 & 0 & 1 & 10 & 0 & 86 & & & \\
\hline & LRR & 29 & 0 & 0 & 0 & 1 & 0 & 0 & 1 & 31 & & & \\
\hline \multicolumn{2}{|c|}{ Total } & 275 & 81 & 0 & 58 & 17 & 23 & 14 & 16 & 484 & & & \\
\hline
\end{tabular}

Note: $n$-sample size, $N$ - number of populations tested, Oth. - other, other genotypes of gametes; Methods of gamete genotype identification: 1, progeny morphometric analysis; 2, electrophoretic analysis of the progeny using biochemical gene markers; 3 , electrophoretic analysis of the progeny using DNA minisatellites; 4, karyological analysis of gametes; 5 , electrophoretic analysis of gametes using diagnostic enzymes; 6 , analysis of gametes with the help of DNA cytophotometry.

Squashed testes were washed off into filter cone with $2 \mathrm{ml}$ of distilled water. Filtering was performed using macroporous filter paper. The filtrate obtained (it should be turbid, which is the marker of successful sample preparation) was centrifuged for $5 \mathrm{~min}$ at $1000 \mathrm{rpm}$. Supernatant with the help of syringe was placed in a clean tube and centrifuged for $15 \mathrm{~min}$ at $5000 \mathrm{rpm}$. After removal of supernatant, the sediment was added with two to three drops of $10 \%$ sucrose, stained by addition of bromphenol blue. Closed tubes were frozen for $12 \mathrm{~h}$. After thawing, the tube was shacked to obtain homogenous turbid suspension.

Gamete classification. The following gamete profiles were considered as normal: a) only haploid gametes of one genotypic class ( $\mathrm{L}$ or $\mathrm{R})$; b) diploid homozygous gametes of one genotypic class (LL or $\mathrm{RR})$. In the profiles of abnormal gametes four of these were distinguished, including nonreduced diploid gametes (LR); a mixture of two classes of haploid gametes in comparable ratios $(\mathrm{L}+\mathrm{R})$, and those with numerical prevalence of one of the classes $(\mathrm{L} \gg \mathrm{R})$; and others (three or more gamete classes, a mixture of diploid gametes, etc.). In all cases not the frequencies of different gamete types were calculated, but the frequencies of individuals, characterized by normal or abnormal gametogenesis.

\section{RESULTS}

\section{Correctness of Gametogenesis in Hybrid Form Rana "esculenta"}

The proportion of the animals producing normal gametes is independent from sex and ploidity and constitutes from $84 \%$ in LR allodiploids to $93 \%$ in LRR allotriploids (Figs. 1, 2; Table 2).

\section{Species Affiliation of the Genome Inherited}

Among the diploid Rana "esculenta" frogs, 67\% were the animals inheriting only the lake frog genome $(\mathrm{LR} \longrightarrow \mathrm{R})$. The proportion of the animals inheriting exclusively the genome of the second parent $(\mathrm{LR} \longrightarrow \mathrm{L})$ was $18 \%$ (Tables 1 and 2, Fig. 1). In terms of species affiliation of the genome inherited, triploid Rana "esculenta" frogs were different. The LLR triploids almost exclusively inherited the genome of pool frog ( $86 \%$ of the individuals); only about $1 \%$ of LLR individuals produced normal gametes with $\mathrm{R}$ genotype. None of the LRR triploids inherited the genome of pool frog (Table 2, Fig. 2). 
(a)

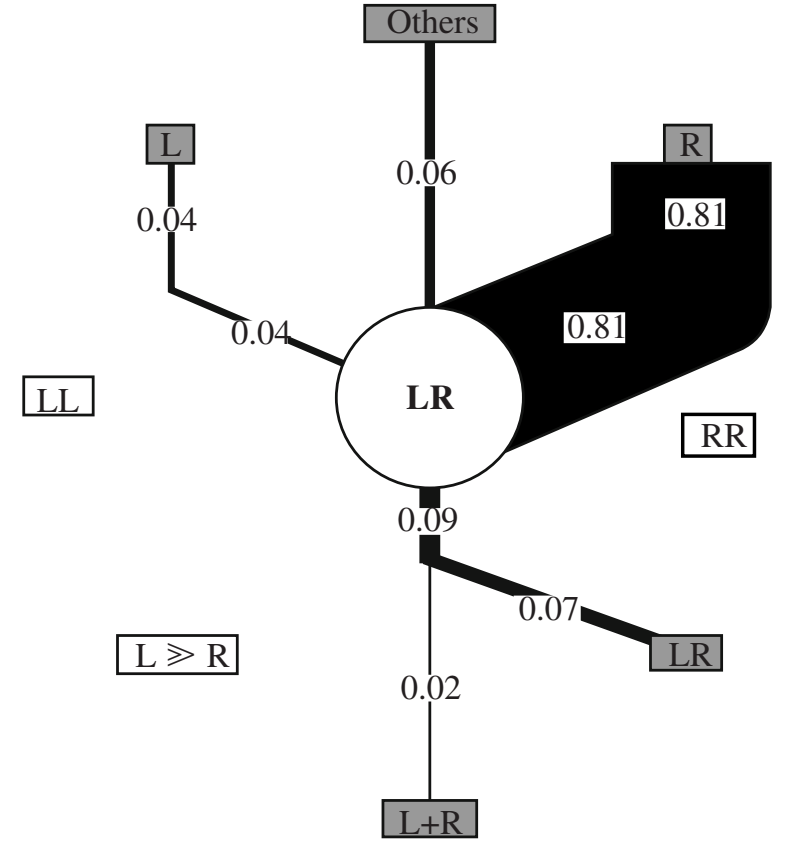

(b)

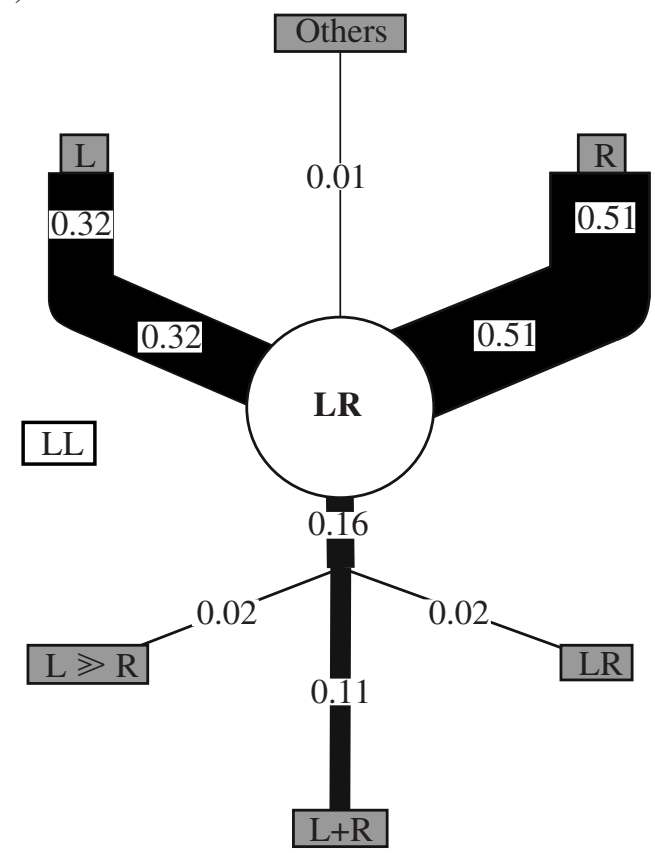

Fig. 1. Distribution of allodiploid females (a) and males (b) in accordance with the mode of inheritance of paternal genomes.

(a)

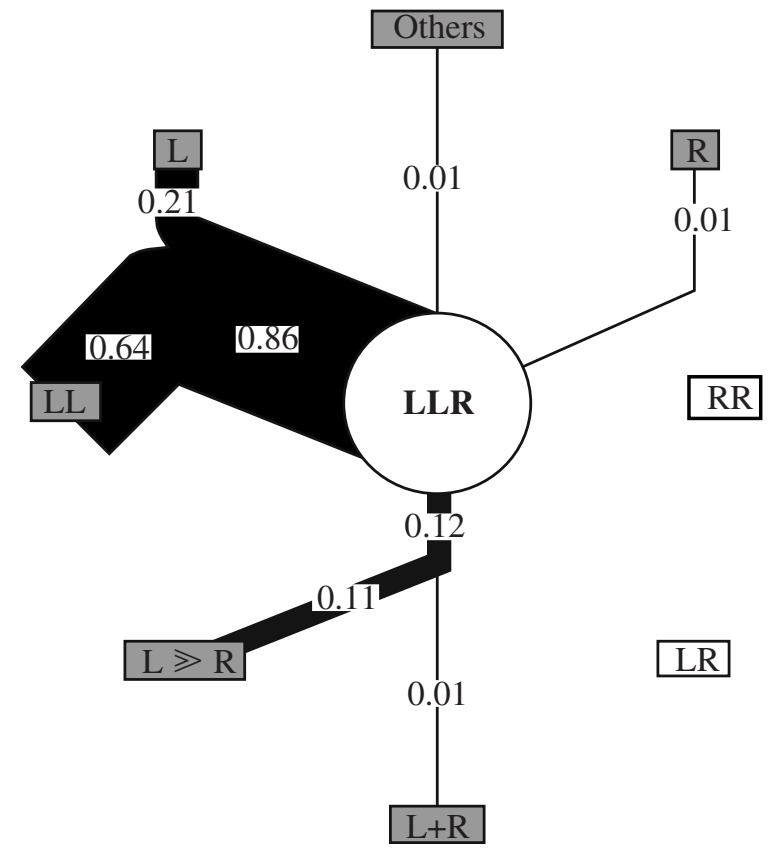

(b)

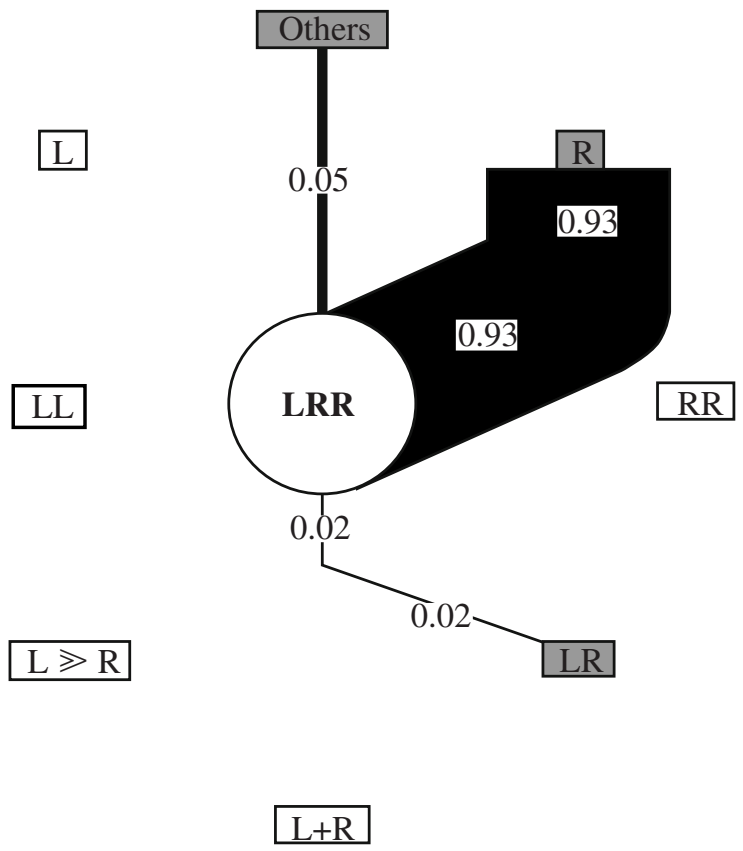

Fig. 2. Distribution of LLR (a) and LRR (b) allotriploids in accordance with the modes of inheritance of parental genomes.

\section{Inheritance in Allodiploid Rana "esculenta" Frogs}

All normal gametes produced by allodiploids had a haploid genotype (Table 2). Among allodiploids, the proportion of individuals inheriting the genome of lake frog was greatly variable: from 13\% (Russia) and 16\%
(Germany) to 53\% (Poland) and 65\% (Ukraine). The data obtained for other countries indicated that inheritance of only lake frog genome was observed. On the territory of Ukraine, Dnieper River basin, inheritance of only the lake-frog genome $(\mathrm{LR} \longrightarrow \mathrm{R})$ was 
Table 2. Frequencies of hybrid Rana "esculenta" frogs producing normal gametes

\begin{tabular}{|c|c|c|c|c|c|c|c|c|c|c|}
\hline \multirow{3}{*}{$\begin{array}{l}\text { Soma } \\
\text { LR }\end{array}$} & \multirow{2}{*}{ Sex } & \multicolumn{9}{|c|}{ Genotypes of gametes produced } \\
\hline & & \multicolumn{2}{|c|}{$\mathrm{R}$} & \multicolumn{2}{|c|}{$\mathrm{L}$} & \multicolumn{2}{|c|}{ LL } & \multicolumn{2}{|c|}{ Total } & $n$ \\
\hline & 우 & 0.810 & 0.029 & 0.043 & 0.015 & - & - & 0.853 & 0.026 & 184 \\
\hline & $\hat{o} \sigma^{\pi}$ & 0.512 & 0.039 & 0.321 & 0.036 & - & - & 0.833 & 0.029 & 168 \\
\hline & $F$ & \multicolumn{2}{|c|}{$36.46 * * *$} & \multicolumn{2}{|c|}{$54.18 * * *$} & \multicolumn{2}{|c|}{-} & \multicolumn{2}{|c|}{0.26} & \\
\hline \multirow[t]{3}{*}{ LLR } & 우 & - & - & 0.5 & 0.3 & 0.3 & 0.2 & 0.8 & 0.2 & 4 \\
\hline & $\hat{0} \hat{\sigma}$ & 0.01 & 0.01 & 0.20 & 0.04 & 0.66 & 0.05 & 0.87 & 0.04 & 86 \\
\hline & $F$ & \multicolumn{2}{|c|}{0.18} & \multicolumn{2}{|c|}{1.61} & \multicolumn{2}{|c|}{2.80} & \multicolumn{2}{|c|}{0.38} & \\
\hline \multirow[t]{3}{*}{ LRR } & 우 & 0.91 & 0.09 & - & - & - & - & 0.91 & 0.09 & 11 \\
\hline & के & 0.94 & 0.04 & - & - & - & - & 0.94 & 0.04 & 31 \\
\hline & $F$ & \multicolumn{2}{|c|}{0.08} & \multicolumn{2}{|c|}{-} & \multicolumn{2}{|c|}{-} & \multicolumn{2}{|c|}{0.08} & \\
\hline
\end{tabular}

Total

\begin{tabular}{|c|c|c|c|c|c|c|c|c|c|c|}
\hline $2 n+3 n$ & $\begin{array}{l}\text { 우 } \\
\text { 숭 }\end{array}$ & $\begin{array}{l}0.799 \\
0.407\end{array}$ & $\begin{array}{l}0.028 \\
0.029\end{array}$ & $\begin{array}{l}0.050 \\
0.249\end{array}$ & $\begin{array}{l}0.015 \\
0.026\end{array}$ & $\begin{array}{l}0.005 \\
0.200\end{array}$ & $\begin{array}{l}0.005 \\
0.024\end{array}$ & $\begin{array}{l}0.854 \\
0.856\end{array}$ & $\begin{array}{l}0.025 \\
0.021\end{array}$ & $\begin{array}{l}199 \\
285\end{array}$ \\
\hline LR & $q q+\widehat{o} \widehat{0}$ & 0.668 & 0.025 & 0.176 & 0.020 & - & - & 0.844 & 0.019 & 352 \\
\hline LLR & & 0.01 & 0.01 & 0.21 & 0.04 & 0.64 & 0.05 & 0.87 & 0.046 & 90 \\
\hline LRR & & 0.93 & 0.04 & - & - & - & - & 0.93 & 0.04 & 42 \\
\hline \multirow[t]{3}{*}{$F$} & LR-LLR & \multicolumn{2}{|c|}{$207.49 * * *$} & \multicolumn{2}{|c|}{0.56} & \multicolumn{2}{|c|}{$248.99 * * *$} & \multicolumn{2}{|c|}{0.30} & \\
\hline & LR-LRR & \multicolumn{2}{|c|}{$17.75^{* *}$} & \multicolumn{2}{|c|}{$28.15^{* *}$} & \multicolumn{2}{|c|}{0.00} & \multicolumn{2}{|c|}{2.77} & \\
\hline & LLR-LRR & \multicolumn{2}{|c|}{$163.48 * * *$} & \multicolumn{2}{|c|}{$26.11^{* *}$} & \multicolumn{2}{|c|}{$99.48 * * *$} & \multicolumn{2}{|c|}{1.22} & \\
\hline Overall & & 0.568 & 0.023 & 0.167 & 0.017 & 0.120 & 0.015 & 0.855 & 0.016 & 484 \\
\hline
\end{tabular}

$* * P<0.01 ; * * * P<0.001$.

observed. Hybrid frogs from the Danube River basin are heterogeneous in this respect. In the populations from Transcarpatian lowlands, inheritance of only lake frog genome was observed ( $\mathrm{LR} \longrightarrow \mathrm{R}$ ), while in the populations from the mouth of the Danube River only pool frog genome was inherited (LR $\longrightarrow$ L). In Ukrainian population from the Don River basin (Severskii Donets) the proportion of hybrids inheriting only the lake frog genome was $10 \%$. Relative to this character, Ukrainian population was similar to Russian populations, which was not surprising, taking into consider- ation the belongings of the populations mentioned to one drainage area.

The gamete profiles produced by diploid hybrid frogs demonstrated statistically significant sex differences. Diploid females of Rana "esculenta" (Fig. 1a) inherited predominantly the lake frog genome $(81 \%)$. Among the diploid males of Rana "esculenta" (Fig. 1b), inheritance of the LR $\longrightarrow$ R type was statistically significantly lower (51\% of the animals) (Table 2, $P<0.001$ ). 


\section{Inheritance in Allotriploid Rana "esculenta"}

No correlation between the genotypes of gametes produced by allotriploid frogs and sex was observed (Table 2). The LLR triploids from Hungary (one population examined) produced diploid gametes with only LL genotype. In all other populations, normal gametes produced by the LLR triploids practically in all cases had haploid L genotype (Fig. 2a).

All normal gametes produced by the LRR triploids (Fig. 2b) had R genotype. Interestingly, gametes produced by two classes of triploids were different. Specifically, the LLR animals produced two classes of normal gametes (L and LL), while LRR animals produced normal gametes of only one class (R).

\section{DISCUSSION}

\section{Species Affiliation of the Genome Inherited}

The data presented in this study give the impression that allodiploid females more often inherit the genome of lake frog than allodiploid males. This illusory difference is caused by summation of the data from different population samples, characterized by different sex structures. Within-population analysis showed that only in one sample obtained from Oder population (Germany) females (one individual) inherited the genome of lake frog, while males (two individuals) inherited the genome of pool frog [9]. No such differences were observed in all other samples.

\section{Modes of Reproduction of Hybrid Forms}

Currently available data point to the existence of two pathways for the mechanisms of reproduction of hybrid forms. The differences involve such traits as sexual structure of hybrid forms, species affiliation of the genome inherited, and reproductive features of allotriploids.

The first mechanism is realized in Poeciliopsis fish [10] and in the genus Bacillus [11]. In these cases hybrid individuals are represented exclusively by females, and always inherit maternal genome. Furthermore, the inheritance is strictly unimodal (the genome of the same species is always inherited). Allodiploids are reproduced through backcrossing to the males of that parental species, whose genome is not inherited. Allotriploids are reproduced either gynogenetically, or parthenogenetically $[7,12]$. Thus, in this case, allodiploids and allotriploids are reciprocally reproductively isolated.

The second mechanism is realized in the fish of the genus Tropidophoxinellus [13], as well as in the green frogs of the genus Rana. In this case, hybrids can be both females and males. Genome of any of parental species can be inherited by hybrids (the mode of inheritance is polymodal). Hybrid individuals can produce both haploid and diploid gametes. Furthermore, diploid gametes can carry two genomes of one species, or have hybrid genotype. Finally, allotriploids produce valid gametes, and are not reproductively isolated from allodiploids.

\section{Origin and Reproduction \\ of Rana "esculenta" Allotriploids}

Currently, the available data evidence that Rana "esculenta allodiploids do not produce diploid homozygous gametes (LL or RR). For this reason, allotriploids can arise only among the progeny of diploid hybrids, producing abnormal gametes with genotype LR. Combination of the later with haploid gametes provides the formation of both triploid genotypes $(\mathrm{LR}+\mathrm{L} \longrightarrow \mathrm{LLR}, \mathrm{LR}+\mathrm{R} \longrightarrow \mathrm{LRR})$. This mechanism of allotriploid development was confirmed for the genus Poeciliopsis [7]. In case of homotypic cross between two hybrids, producing diploid gametes, the appearance of both symmetric (LR + LR $\longrightarrow$ LLRR) and asymmetric (LL + LR $\longrightarrow$ LLLR) allotetraploids is possible. These allotetraploids with low frequencies can be really found in natural populations $[14,15]$. Thus, allotriploid Rana "esculenta" individuals serve as markers of abnormal gametogenesis in this hybrid form.

Theoretically, two ways for reproduction of triploids with genotype LLR $(\mathrm{L}+\mathrm{LR} \longrightarrow$ LLR or LL $+\mathrm{R} \longrightarrow$ LLR) are possible. The second way, as it was already mentioned above, is known for the only population of ER type from Hungary. In this population, allotriploids (100\% ô oे LLR) are reproduced through crosses with lake frog females. All progeny of these crosses has paternal genotype LLR and consists of only males. Thus, this population system is stable.

It is suggested that reproduction of LRR triploids requires another mechanism. Actually, the LRR triploids produce no diploid gametes with RR genotype. Reproduction of such allotripoids is possible using the only way ( $L R+R$ ? LRR). It can be expected that in the populations, where allodiploids produce only haploid gametes, no LRR allotriploids can appear, or be reproduced. It can be suggested that LLR allotriploids have more chances for successful reproduction than LRR allotriploids. This suggestion agrees with the data available. As can be seen from Table 1, the ratio between the population numbers of LLR and LRR allotriploids was almost $2: 1$.

\section{ACKNOWLEDGMNTS}

We thank all colleagues who helped preparing the present paper: E.I. Zhalai, A.I. Alekseeva, V.I. Radchenko, V.Yu. Reminnyi (Kiev), A.I. Zinenko (Khar'kov), and A.S. Matveev (Vilkovo).

\section{REFERENCES}

1. Berger, L., Is the Pool Frog Rana esculenta Complex an Ordinary Hybrid?, Ekologiya, 1976, no. 2, pp. 37-43. 
2. Graf, J.D. and Muller, W.P., Experimental Gynogenesis Provides Evidence of Hybrid Reproduction in the Rana esculenta Complex, Experientia, 1979, vol. 35, pp. 1574-1576.

3. Schultz, R.J., Hybridization, Unisexuality and Polyploidy in the Teleost Poeciliopsis (Poeciliidae) and Other Vertebrates, Am. Nat., 1969, vol. 103, pp. 605-619.

4. Morozov-Leonov, S.Yu., Genetic Processes in Hybrid Populations of Green Frog Rana esculenta Complex of Ukraine, Extended Abstract of Cand. Sci. (Biol.) Dissertation, Kiev: Institute of Cell Biology and Genetic Engineering, 1998, p. 24.

5. Vinogradov, A.E., Borkin, L.J., Günther, R., and Rosanov, J.M., Two Germ Cell Lineages with Genomes of Different Species in One and the Same Animal, Hereditas, 1991, vol. 114, pp. 245-251.

6. Vinogradov, A.E., Borkin, L.J., and Günther, R., Genome Elimination in Diploid and Triploid Rana esculenta Males: Cytological Evidence from DNA Flow Cytometry, Genome, 1990, vol. 33, pp. 619-627.

7. Quattro, J.M., Avise, J.C., and Vrijenhoek, R.C., Mode of Origin and Sources of Genotypic Diversity in Triploid Gynogenetic Fish Clones (Poeciliopsis: Poeciliidae), Genetics, 1992, vol. 130, pp. 621-628.

8. Mezhzherin, S.V. and Peskov, V.N., Biochemical Variation and Genetic Differentiation in a Lake Frog Rana ridibunda Pall. Population, Tsitol. Genet., 1992, vol. 26, no. 1, pp. 43-48.

9. Berger, L., On the Origin of Genetic Systems in European Water Frog Hybrids, Zool. Pol., 1988, vol. 35, nos. 1-4, pp. 5-32.

10. Avise, J.C. and Vrijenhoek, R.C., Mode of Inheritance and Variation of Mitochondrial DNA in Hybrid Fishes of the Genus Poeciliopsis, Mol. Biol. Evol., 1987, vol. 4, no. 5, pp. 514-525.

11. Tinti, F., Mantovani, B., and Scali, V., Reproductive Features of Homospecific Hybridally Derived Stick Insects Suggest How Unisexuals Can Evolve, J. Evol. Biol., 1995, vol. 8, pp. 81-92.

12. Mantovani, B., Satellite Sequence Turnover in Parthenogenetic Systems: The Apomictic Triploid Hybrid Bacillus lynceorum (Insecta, Phasmatodea), Mol. Biol. Evol., 1998, vol. 15, no. 10, pp. 1288-1297.

13. Pala, I. and Coelho, M.M., Contrasting Views over a Hybrid Complex: Between Speciation and Evolutionary "Dead-End", Gene, 2005, vol. 347, pp. 283-294.

14. Borkin, L.J., Korshunov, A.V., Lada, G.A., et al., Mass Occurrence of Polyploid Green Frogs (Rana esculenta
Complex) in Eastern Ukraine, Russ. J. Herpetol., 2004, vol. 11, no. 3, pp. 194-213.

15. Christiansen, D.G., Fog, K., Pedersen, B.V., and Boomsma, J.J., Reproduction and Hybrid Load in AllHybrid Populations of Rana esculenta Water Frogs in Denmark, Evolution, 2005, vol. 59, no. 6, pp. 1348-1361.

16. Berger, L., Some Peculiar Phenomena in European Water Frogs, Zool. Pol., 1994, vol. 35, nos. 3-4, pp. 267-280.

17. Günther, R., Uzzell, T., and Berger, L., Inheritance Patterns in Triploid Rana "esculenta", Mitt. Zool. Mus. Berlin, 1979, vol. 55, pp. 35-57.

18. Bucci, S., Ragghianti, M., Mancino, G., et al., Lampbrush and Mitotic Chromosomes of the Hemiclonally Reproducing Hybrid Rana esculenta and Its Parental Species, J. Exptl. Zool., 1990, vol. 255, pp. 37-56.

19. Uzzell, Th., Hotz, H., and Berger, L., Genome Exclusion in Gametogenesis by an Interspecific Rana Hybrid: Evidence from Electrophoresis of Individual Oocytes, $J$. Exptl. Zool., 1980, vol. 214, pp. 251-259.

20. Graf, J.D., Karch, F., and Moreillon, M.-C., Biochemical Variation in the Rana esculenta Complex: A New Hybrid Form Related to Rana perezi and Rana ridibunda, Experientia, 1977, vol. 33, pp. 1582-1583.

21. Berger, L., Uzzell, T., and Hotz, H., Sex Determination and Sex Ratios in Western Palearctic Water Frogs: XX and XY Female Hybrids in the Pannonian Basin?, Proc. Acad. Nat. Sci. Phila, 1991, vol. 140, no. 1, pp. 220-239.

22. Tunner, H.G. and Heppich-Tunner, S., Genome Exclusion and Two Strategies of Chromosome Duplication in Oogenesis of a Hybrid Frog, Naturwissenschaften, 1991, vol. 78, pp. 32-34.

23. Tunner, H.G., The Inheritance of Morphology and Electrophoretic Markers from Homotypic Crosses of the Hybrid Rana esculenta, Mitt. Zool. Mus. Berlin, 1979, vol. 55, pp. 89-109.

24. Tunner, H.G. and Heppich-Tunner, S., A New Population System of Water Frogs Discovered in Hungary, in Proc. 6th Ord. Gen. Meet. S.E.H., Budapest, 1992, pp. 453-460.

25. Borkin, L.Ya., Vinogradov, A.E., Rozanov, Yu.M., and Tsaune, I.A., Polyclonal Inheritance in Hybrid Rana esculenta Complex: Evidence from DNA Flow Cytometry, Dokl. Akad. Nauk SSSR, 1987, vol. 295, no. 5, pp. 1261-1264.

26. Vinogradov, A.E., Rozanov, Yu.M., Tsaune, I.A., and Borkin, L.Ya., Elimination of One of the Parental Genomes before Premeiotic DNA Synthesis in the Hybrid Rana esculenta Species, Tsitologiya, 1988, vol. 30, no. 6, pp. 691-697. 